\title{
The Effects of Static and Dynamic Stretching Exercises on Ankle Muscle Strength and Balance
}

\author{
Aydın BALCI ${ }^{1}$, Mehmet Mesut ÇELEBí ${ }^{\circledR}$, Murat Ali ZERGEROĞLU² ${ }^{\mathbb{D}}$, \\ Rüştü Süleyman GÜNER ${ }^{2}$ \\ ${ }^{1}$ Yıldırım Beyazıt University, Yenimahalle Training and Research Hospital, Sports Medicine Department, \\ Ankara, Turkey \\ ${ }^{2}$ Ankara University, School of Medicine, Sports Medicine Department, Ankara, Turkey.
}

Original Article

Received: 11.01 .2020
Accepted: 25.03.2020

Online Publishing: 30.06 .2020

\begin{abstract}
Different types of stretching exercises are utilized prior to physical exercises as a part of warming-up. The purpose of this study is to investigate the effects of the dynamic and static stretching exercises on ankle muscle strength and single-leg balance. Twenty healthy male participants, who were between 25 and 30 years old and did not have a previous ankle injury, were included in the study. This study is a cross-over designed study. Isokinetic ankle muscle strength tests and single-leg balance tests were applied to the participants after different intervention protocols (two intervention protocols and one control protocol) on 6 different days. With isokinetic testing, peak torque and average power were measured at $60 \% \mathrm{~s}$ and $120 \%$ angular velocities. The tests were performed to the participants after static stretching, dynamic stretching and for a resting period without stretching. The order of stretching intervention was determined randomly. The Peak Torque results of the $120 \%$ angular velocity isokinetic strength test after the dynamic stretching exercises were found significantly improved than those without stretching exercises $(p<0.05)$. A significant difference was not determined in Average Power and Peak Torque at $60 \%$ values $(p>0.05)$. It was also shown that the dynamic stretching significantly enhanced the balance scores $(p<0,05)$. In the current study, dynamic stretching exercises were found to have positive effects on isokinetic peak torque and balance scores.
\end{abstract}

Keywords: Muscle Strength, Postural Balance, Static Stretching, Dynamic Stretching.

\section{INTRODUCTION}

As well as various external factors; some individual factors such as strength, balance, flexibility are associated with sports performance (Cronin and Sleivert, 2005; Hrysomallis, 2011). The relationship between these factors is a matter of curiosity. There are various types of stretching exercises that are used before physical activity. Static stretching (SS) and dynamic stretching (DS) exercises are some of them. Static stretching is the type of stretching exercise often preferred by the athletes. Currently, many studies claim that both static and dynamic stretch affect athletic performance. Some researches, about the SS before physical activity, claimed that it caused a decrease in the vertical jump height (Bradley et al., 2007), sprint (Gelen, 2010) and isokinetic muscle strength (Cramer et al., 2006). The adverse effects of the SS are thought to be caused by mechanical (Herda et al., 2008) or neuromuscular factors (Hough et al., 2009). On the other hand, some studies reported that SS had no 
significant effect (Beedle et al., 2008; Handrakis et al., 2010) or an enhancement effect on performance (Costa et al., 2009). It is thought that conflicting opinions are related to different factors such as duration and intensity of stretching and study populations (Behm \& Chaouachi, 2011).

Dynamic stretching has become more popular due to contradictions in the literature about the effects of SS. The effects of dynamic stretching on joint mobility range of motion (ROM) and performance parameters were examined in some studies. It is stated that the DS improves ROM (Beedle and Mann, 2007), sprint (Fletcher and Anness, 2007), power (Manoel et al., 2008), isokinetic muscle strength (Sekir et al., 2010) and jump (Hough et al., 2009; Jaggers et al., 2008).

Besides, stretching exercises may affect the balance like as well as strength and power. Behm et al., (2004) reported that SS decreased the balance ability and adverse effects could be related to the changes in the length and stiffness of muscle tendons. However, there is a lack of knowledge in the literature about the effect of DS on balance. Furthermore, it is known that ankle plantar and dorsal flexor muscles are crucial to maintain the balance (Di Giulio et al., 2009; Jeon et al., 2013; Yaggie \& McGregor, 2002).

To the authors' knowledge, there is not any study investigating the application of DS to the ankle plantar and dorsal flexor muscles on balance. The purpose of this study is to investigate the effects of different stretching exercises on the ankle plantar and dorsal flexor muscle strength and single-leg balance.

\section{METHOD}

Participants: Twenty sedentary men $(27.6 \pm 1.2$ years, $179 \pm 5.6 \mathrm{~cm}, 81.8 \pm 10.3 \mathrm{~kg}, 25.3 \pm$ 2.4 BMI) were participated in this study. Stretching exercises and tests were applied to the dominant leg of the participants. Patients with acute or chronic ankle injury and ankle ROM limitation were excluded from the study. This study was designed according to the Declaration of Helsinki, which printed in the British Medical Journal (18 July 1964). Ethical approval was obtained from the Ankara University Ethical Committee (26.08.2013/11-46913). All participants were fully informed about the study and they all signed written informed consent form.

Materials and Procedures: This study is a cross-over designed study. Before the data gathering, each participant underwent in a physical examination and they received orientation training about the isokinetic tests and balance tests. Following the orientation, the participants implemented the tests on different days in the same order. Interventions before the tests are as follows: (a) the balance test after warm-up without stretching [control protocol], (b) balance test after warm-up and static stretching, (c) balance test after warm-up and dynamic stretching, (d) isokinetic muscle test after warm-up without stretching [control protocol], (e) isokinetic muscle test after warm-up and static stretching, (f) isokinetic muscle test after warm-up and dynamic stretching. In the current study, at least 48 hours interval was given between the tests to eliminate the learning effect. The tests were carried out on six different days and completed in a total of two weeks. All study procedures were performed between 
16:00 and 20:00. The average duration of each static and dynamic stretching exercise took 5 minutes. Therefore, each participant was given a rest for 5 minutes in the control intervention before tests.

Static Stretching Protocol: Before the static stretching session, each participant performed a warm-up exercise with a bicycle ergometer at 60 RPM and 50 Watt for 5 minutes. For stretching the ankle plantar and dorsal flexor muscles of the dominant leg, two static stretching exercises were applied to both muscle groups. The participants repeatedly practiced both exercises for 20 seconds in the point that accepted as their moderate discomfort level. Between each stretching repetition, it was asked to keep the ankle in the neutral position for 15 seconds. In total, the static stretching exercise lasted 5 minutes (Sekir et al., 2010).

Dynamic Stretching Protocol: Before the dynamic stretching session, each participant performed the warm-up exercise with a bicycle ergometer at 60 RPM and 50 Watt for 5 minutes. As dynamic stretching, two stretching exercises were performed in both on standing and sitting poses for plantar and dorsal flexor muscle groups. Dynamic stretching exercises were performed with the contraction of antagonist muscle groups of target muscles. Before each stretching exercise, the antagonist muscles were kept contracted for 2 seconds to stretch the target muscle. Then, the participants were asked to contract antagonist of the target muscles 5 times slowly and 10 times as strongly and quickly as possible. Between each stretching repetition, it was asked to keep the ankle in the neutral position for 15 seconds of resting period. In total, the dynamic stretching exercise lasted about 5 minutes (Sekir et al., 2010).

\section{Data Collection:}

Isokinetic Test Protocol: Biodex Isokinetic System Pro was used for isokinetic concentric peak torque (PT) and average power (AP) measurements of plantar and dorsal flexor muscles in the ankle. The participant's ankle to be tested was placed on the device's plantar flexor and dorsal flexor plate. Afterward, the participants performed five ankle flexion and extension exercises at $60 \% \mathrm{~s}$ angular velocity and ten ankle flexion and extension exercises at $120 \%$ angular velocity. A 1-minute rest was given between each angular velocity. The PT and AP values of each test were used in the data analysis.

Balance Test Protocol: The balance test was carried out with the Biodex Balance Systems SD device. This device consists of a moving circular platform and a pivot shaft under the platform. The platform that measures the center of gravity changes is connected to a computer. The changes are determined as "balance score" according to their distance from the starting point. The changes are calculated as anteroposterior (A-P), mediolateral (M-L) and total $(\mathrm{T})$ score. The decrease in the balance scores indicates a better balance ability. "Athletic Single-Leg Test" procedure was conducted to the participants. The participants were asked to stand on the platform three times for 20 seconds with their dominant leg on the standing platform of the device. A 1-minute rest was given between each test. Anteroposterior (A-P), mediolateral (M-L) and total (T) balance scores were used for data analysis. 
Balcı A., Çelebi M.M., Zergeroğlu M.A. \& Güner R.S. (2020). The Effects of static and dynamic stretching exercises on ankle muscle strength and balance. Spor Bilimleri Araştırmaları Dergisi, 5(1), 27-34.

Data Analysis: The sample size was determined to be 0.80 power, 0.05 alpha and 0.25 effect size (R 3.0.1 open source program). The Friedman test was used to investigate the differences between the three protocols. Post-Hoc Tests were performed for paired comparison. All statistical analysis was performed with the arrangement of importance to $\mathrm{p}<0.05$ by SPSS in Windows 11.5 operating system.

\section{RESULTS}

When the dynamic stretching protocol and the control protocol were compared, there was a significant increase in plantar flexion peak torque values at $120^{\circ} / \mathrm{s}$ angular velocity after dynamic stretching $(p<0.05)$. There was not any significant difference in other isokinetic strength measurements (Table 1-2).

Table 1. Isokinetic test Peak Torque (PT) values of three protocols. Values are median (min-max)

\begin{tabular}{lllll}
\hline & Static & Dynamic & Non-Stretch & $p$ value \\
\hline $60^{\circ} / \mathrm{sec}$ PF-PT (Nm) & $40.5(21.9-68.3)$ & $47(23.5-76.5)$ & $39.8(17-77.8)$ & 0.157 \\
$60 \%$ sec DF-PT (Nm) & $33.9(25.4-55.5)$ & $38.75(26.1-59.5)$ & $32.4(28.4-54.1)$ & 0.247 \\
$120^{\circ} / \mathrm{sec}$ PF-PT (Nm) & $30.9(20.7-48.6)$ & $36.5(21-68.8)$ & $31.5(19.6-52)$ & $0.022^{*}$ \\
$120^{\circ}$ sec DF-PT (Nm) & $24.7(15.7-52.4)$ & $29.85(19.5-49.8)$ & $27.4(19.9-45.5)$ & 0.705
\end{tabular}

* Significant difference between dynamic stretching and non-stretching protocols $(p<0.05)$ (Friedman test and post-hoc tests) ** PF= Plantar Flexor, DF= Dorsal Flexor, $\mathrm{PT}=$ Peak Torque

Table 2. Isokinetic test Average Power (AP) values of three protocols. Values are median (min-max)

\begin{tabular}{lllll}
\hline & Static & Dynamic & Non-Stretch & $p$ value \\
\hline $60^{\circ} / \mathrm{sec}$ PF-AP (W) & $16.6(6.9-34.8)$ & $20.45(6.8-42.9)$ & $17.65(3-39.9)$ & 0.387 \\
$60^{\circ} / \mathrm{sec}$ DF-AP (W) & $20.5(11.3-29.4)$ & $19.7(13.8-33.9)$ & $19.6(16.1-28.2)$ & 0.359 \\
$120 \%$ sec PF-AP (W) & $18(7.2-34)$ & $20(3.2-43.9)$ & $14.8(3.8-45.1)$ & 0.074 \\
$120 \%$ sec DF-AP (W) & $19.3(11.6-34.5)$ & $19.55(11.9-37.4)$ & $19.1(17.1-27.3)$ & 0.287 \\
\hline
\end{tabular}

* PF= Plantar Flexor, DF= Dorsal Flexor, $\mathrm{AP}=$ Average Power

When the dynamic stretching protocol and the control protocol were compared it was seen to cause a significant change in the balance scores after dynamic stretching $(p<0.05)$. When the control protocol was compared with the static stretching protocol, no significant difference was found in the balance scores $(p>0.05)$ (Table 3).

Table 3. Balance values of three protocols. Values are median (min- max)

\begin{tabular}{lllll}
\hline & Static & Dynamic & Non-Stretch & $p$ value \\
\hline Balance Total & $1.1(0.7-1.6)$ & $1(0.5-1.5)$ & $1.2(0.8-1.7)$ & $0.008^{*}$ \\
Balance A-P & $0.8(0.5-1.3)$ & $0.75(0.2-1.3)$ & $1(0.6-1.5)$ & $0.003 *$ \\
Balance M-L & $0.5(0.4-1.2)$ & $0.5(0.1-0.9)$ & $0.6(0.2-0.9)$ & 0.506
\end{tabular}

* Significant difference between dynamic stretching and non-stretching protocols $(p<0.05)$ (Friedman test and post-hoc tests). ** $\mathrm{A}-\mathrm{P}=$ Anteroposterior, $\mathrm{M}-\mathrm{L}=$ Mediolateral. 


\section{DISCUSSION}

Some studies in the literature have investigated the effects of stretching types on balance and performance parameters. According to our literature review, this study is the first to investigate the isokinetic parameters on the plantar and dorsal flexor muscles of the dynamic stretching ankle and to focus on the single-leg balance skill scores after applying dynamic stretching exercises at the muscles. In the present study, it was detected that dynamic stretching exercises significantly increased the values of PF-PT at $120 \%$, and this data is consistent with previous studies. However, in some studies, it was observed that there was no significant effect the dynamic stretching on the performance such as vertical jump height and isometric peak torque (Christiensen and Nordstrom, 2008; Herda et al., 2008). The intensity (e.g. frequency, range of motion) and duration of dynamic stretching may have affected the results of previous investigations. In the literature, there is no evidence that dynamic stretching deteriorated the performance. Our results also showed that the dynamic stretching does not have any adverse effect on muscle strength. Furthermore, Beedle and Mann reported that dynamic stretching contributed to flexibility (2007).

It was reported that static stretching caused a decrease in performance (Gelen, 2010; Herda et al., 2010; Sekir et al., 2010). Nevertheless, in some studies static stretching was shown to have no significant effect (Beedle et al., 2008; Winke et al., 2010). In our study, static stretching was found to have no significant effect on peak torque and average power and is consistent with some of the literature.

It is suggested that short-term stretching times do not affect performance. In some studies, with shortterm static stretching (30-120 seconds), no significant change in power or torque was shown (Molacek et al., 2010; Torres et al., 2008). In our study, static stretching for a short-term (20 sec) was applied to each muscle group. It is reported that a 40 -second static stretching caused more deterioration in muscle performance than a 20 -second static stretching exercise (Franco et al., 2008). However, there are also studies which show that deteriorations in isokinetic muscle parameters occur after 20 seconds of static stretching exercise is repeated 2 times (Sekir et al., 2010). Thus, it is understood that the reasons for the conflicting literature cannot be explained only by different stretching times. The types of contractions, stretching intensity and population are also stated as considerable effects (Behm \& Chaouachi, 2011).

In the present study, a significant improvement was found in the A / P and Total Balance scores after dynamic stretching exercises. Similar results were reported by Chatzopoulos et al. (2014). It is suggested that the dynamic stretching increases muscle temperature (Fletcher and Jones, 2004), increases neural conduction (Herda et al., 2008; Jaggers et al., 2008) and it can be an explanation of the balance increase.

Although the balance scores improved after the static stretching exercise, this difference was not statistically significant. In some of the previous studies, it was determined that the static stretching had a negative effect on the balance (Behm et al., 2004; Nagano et al., 2006), and in some cases, it had a positive effect (Costa et al., 2009; Handrakis et al., 2010). In one of the previous studies 3 repetitive static stretching for 15 seconds (Costa et al., 2009) and in the other a total of 3 minutes of static stretching to the gastrocnemius were applied (Nagano et al., 2006). Stretching duration may be the explanation of this conflict. Moreover, to avoid the learning effect, it was thought that the duration between two balance tests should be at least 48 hours (Gribble et al., 2007). In the present study, at least 48 hours interval was given between the tests to eliminate the learning effect. The differences in the duration of static stretching exercises, the effect of muscle fatigue on balance, and the learning effect are accepted as the possible reasons for different outcomes. 
Balcı A., Çelebi M.M., Zergeroğlu M.A. \& Güner R.S. (2020). The Effects of static and dynamic stretching exercises on ankle muscle strength and balance. Spor Bilimleri Araştırmaları Dergisi, 5(1), 27-34.

\section{CONCLUSIONS}

According to these results, we concluded that dynamic stretching exercises improved balance ability and made an increase in $120 \%$ s in ankle plantarflexion concentric muscle strength. Since there is no harmful effect on the isokinetic parameters and it improves the balance skill, dynamic stretching exercises can be recommended to improve performance before the exercises that require balance and strength.

\section{REFERENCES}

Beedle, B., Rytter, S. J., Healy, R. C. \& Ward, T. R. (2008). Pretesting static and dynamic stretching does not affect maximal strength. The Journal of Strength \& Conditioning Research, 22(6), 1838-1843. https://doi.org/10.1519/JSC.0b013e3181821bc9.

Beedle, B. B. \& Mann, C. L. (2007). A Comparision of two warm-ups on joint range of motion. The Journal of Strength \& Conditioning Research, 21(3), 776-779.

Behm, D. G., Bambury, A., Cahill, F. \& Power, K. (2004). Effect of acute static stretching on force, balance, reaction time, and movement time. Medicine \& Science in Sports \& Exercise, 36(8), 1397-1402. https://doi.org/10.1249/01.MSS.0000135788.23012.5F.

Behm, D. G. \& Chaouachi, A. (2011). A review of the acute effects of static and dynamic stretching on performance. European Journal of Applied Physiology, 111(11), 2633-2651. https://doi.org/10.1007/s00421-011-1879-2.

Bradley, P. S., Olsen, P. D. \& Portas, M. D. (2007). The effect of static, ballistic, and proprioceptive neuromuscular facilitation stretching on vertical jump performance. Journal of Strength and Conditioning Research, 21(1), 223-226. https://doi.org/10.1519/R-21046.1.

Chatzopoulos, D., Galazoulas, C., Patikas, D. \& Kotzamanidis, C. (2014). Acute effects of static and dynamic stretching on balance, agility, reaction time and movement time. Journal of Sports Science \& Medicine, 13(2), 403-409.

Christensen, B. K. \& Nordstrom, B. J. (2008). The effects of proprioceptive neuromuscular facilitation and dynamic stretching techniques on vertical jump performance. The Journal of Strength \& Conditioning Research, 22(6), 1826-1831. https://doi.org/10.1519/JSC.0b013e31817ae316.

Costa, P. B., Graves, B. S., Whitehurst, M. \& Jacobs, P. L. (2009). The acute effects of different durations of static stretching on dynamic balance performance. The Journal of Strength \& Conditioning Research, 23(1), 141-147. https://doi.org/10.1519/JSC.0b013e31818eb052.

Cramer, J. T., Housh, T. J., Coburn, J. W., Beck, T. W. \& Johnson, G. O. (2006). Acute effects of static stretching on maximal eccentric torque production in women. Journal of Strength and Conditioning Research, 20(2), 354-358.

Cronin, J. \& Sleivert, G. (2005). Challenges in understanding the influence of maximal power training on improving athletic performance. Sports Medicine, 35(3), 213-234.

Di Giulio, I., Maganaris, C. N., Baltzopoulos, V. \& Loram, I. D. (2009). The proprioceptive and agonist roles of gastrocnemius, soleus and tibialis anterior muscles in maintaining human upright posture. The Journal of Physiology, 587(10), 2399-2416. https://doi.org/10.1113/jphysiol.2009.168690. 
Balcı A., Çelebi M.M., Zergeroğlu M.A. \& Güner R.S. (2020). The Effects of static and dynamic stretching exercises on ankle muscle strength and balance. Spor Bilimleri Araştırmaları Dergisi, 5(1), 27-34.

Fletcher, I. M. \& Anness, R. (2007). The acute effects of combined static and dynamic stretch protocols on fiftymeter sprint performance in track-and-field athletes. Journal of Strength and Conditioning Research, 21(3), 784-787.

Fletcher, I. M. \& Jones, B. (2004). The effect of different warm-up stretching protocols on 20 meters sprint performance in trained rugby union players. The Journal of Strength \& Conditioning Research, 18(4), 885-888.

Franco, B. L., Signorelli, G. R., Trajano, G. S. \& de Oliveira, C. G. (2008). Acute effects of different stretching exercises on muscular endurance. The Journal of Strength \& Conditioning Research, 22(6), 1832-1837. https://doi.org/10.1519/JSC.0b013e31818218e1.

Gelen, E. (2010). Acute effects of different warm-up methods on sprint, slalom dribbling, and penalty kick performance in soccer players. The Journal of Strength \& Conditioning Research, 24(4), 950-956. https://doi.org/10.1519/JSC.0b013e3181cb703f.

Gribble, P. A., Tucker, W. S. \& White, P. A. (2007). Time-of-day influences on static and dynamic postural control. Journal of Athletic Training, 42(1), 35-41.

Handrakis, J. P., Southard, V. N., Abreu, J. M., Aloisa, M., Doyen, M. R., Echevarria, L. M. \& Douris, P. C. (2010). Static stretching does not impair performance in active middle-aged adults. The Journal of Strength \& Conditioning Research, 24(3), 825-830. https://doi.org/10.1519/JSC.0b013e3181ad4f89.

Herda, T., Cramer, J. T., Ryan, E. D., McHugh, M. P. \& Stout, J. R. (2008). Acute effects of static versus dynamic stretching on isometric peak torque, electromyography, and mechanomyography of the biceps femoris muscle. The Journal of Strength \& Conditioning Research, 22(3), 809-817. https://doi.org/10.1519/JSC.0b013e31816a82ec.

Herda, T., Ryan, E., Costa, P., Walter, A., Hoge, K., Uribe, B. \& Cramer, J. T. (2010). 4 Acute effects of passive stretching and vibration on the electromechanical delay and musculotendinous stiffness of the plantar flexors. Electromyography \& Clinical Neurophysiology, 50(6), 277-288.

Hough, P. A., Ross, E. Z. \& Howatson, G. (2009). Effects of dynamic and static stretching on vertical jump performance and electromyographic activity. The Journal of Strength \& Conditioning Research, 23(2), 507-512. https://doi.org/ 10.1519/JSC.0b013e31818cc65d.

Hrysomallis, C. (2011). Balance ability and athletic performance. Sports Medicine, 41(3), 221-232. https://doi.org/ 10.2165/11538560-000000000-00000.

Jaggers, J. R., Swank, A. M., Frost, K. L. \& Lee, C. D. (2008). The acute effects of dynamic and ballistic stretching on vertical jump height, force, and power. The Journal of Strength \& Conditioning Research, 22(6), 1844-1849. https://doi.org/ 10.1519/JSC.0b013e3181854a3d.

Jeon, H.-S., Hwang, S. \& Woo, Y.-K. (2013). The effect of ankle and knee immobilization on postural control during standing. The Knee, 20(6), 600-604. https://doi.org/ 10.1016/j.knee.2012.09.001.

Manoel, M. E., Harris-Love, M. O., Danoff, J. V. \& Miller, T. A. (2008). Acute effects of static, dynamic, and proprioceptive neuromuscular facilitation stretching on muscle power in women. The Journal of Strength \& Conditioning Research, 22(5), 1528-1534. https://doi.org/ 10.1519/JSC.0b013e31817b0433.

Molacek, Z. D., Conley, D. S., Evetovich, T. K. \& Hinnerichs, K. R. (2010). Effects of low-and high-volume stretching on bench press performance in collegiate football players. The Journal of Strength \& Conditioning Research, 24(3), 711-716. https://doi.org/ 10.1519/JSC.0b013e3181c7c242.

Nagano, A., Yoshioka, S., Hay, D. C., Himeno, R. \& Fukashiro, S. (2006). Influence of vision and static stretch of the calf muscles on postural sway during quiet standing. Human Movement Science, 25(3), 422-434.

Sekir, U., Arabaci, R., Akova, B. \& Kadagan, S. (2010). Acute effects of static and dynamic stretching on leg flexor and extensor isokinetic strength in elite women athletes. Scandinavian Journal of Medicine \& Science in Sports, 20(2), 268-281. https://doi.org/ 10.1111/j.1600-0838.2009.00923.x 
Balcı A., Çelebi M.M., Zergeroğlu M.A. \& Güner R.S. (2020). The Effects of static and dynamic stretching exercises on ankle muscle strength and balance. Spor Bilimleri Araştırmaları Dergisi, 5(1), 27-34.

Torres, E. M., Kraemer, W. J., Vingren, J. L., Volek, J. S., Hatfield, D. L., Spiering, B. A., . . Anderson, J. M. (2008). Effects of stretching on upper-body muscular performance. The Journal of Strength \& Conditioning Research, 22(4), 1279-1285. https://doi.org/ 10.1519/JSC.0b013e31816eb501.

Winke, M. R., Jones, N. B., Berger, C. G. \& Yates, J. W. (2010). Moderate static stretching and torque production of the knee flexors. The Journal of Strength \& Conditioning Research, 24(3), 706-710. https://doi.org/ 10.1519/JSC.0b013e3181c7c557.

Yaggie, J. A. \& McGregor, S. J. (2002). Effects of isokinetic ankle fatigue on the maintenance of balance and postural limits. Archives of Physical Medicine and Rehabilitation, 83(2), 224-228.

Except where otherwise noted, this paper is licensed under a Creative Commons Attribution 4.0 International license. 